\title{
Methodological concerns and their solutions in third-age language learning studies
}

\author{
Mara van der Ploeg, Merel Keijzer, and Wander Lowie \\ University of Groningen
}

\begin{abstract}
With the average life expectancy in especially developed countries steadily increasing, healthy ageing is prioritised on the research agenda. Various studies have looked into bilingualism as a possible anti-ageing tool to delay the onset of symptoms of degenerative diseases like Alzheimer's, with as perhaps the most promising recent line of work intervention studies that introduce bilingual experiences to seniors in the form of foreign language courses meant to induce a protective effect on cognitive decline.

Unfortunately, the scant studies available have not found convincing results, most likely due to several pitfalls in their designs, one of the most important being that method of instruction is rarely specified or controlled for. In this paper, we identify methodological concerns that need to be addressed when conducting experimental work related to third-age language learning, resulting in a research agenda for third-age language learning studies.
\end{abstract}

Keywords: healthy ageing, critical foreign language gerontology, seniors, third-age language learning, English as a foreign language (EFL), implicit/ explicit language teaching, cognition

\section{Introduction}

The world's population is growing old. In 2017, 25\% of Europe's population was over the age of 60 and it is estimated that by 2050 all regions of the world, except Africa, will have such populations (United Nations, 2017). Ageing is seen as one of the greatest social and economic challenges of the 21st century (He, Goodkind, \& Kowal, 2016), and is mainly being tackled by the medical sciences. But ageing is complex and ideally approached from various research perspectives; it is generally accepted that health is related to well-being and a purpose in life (Hill \& Turiano, 2014). Most recently, foreign language learning has been identified 
as a potentially important factor affecting health and well-being in older adulthood (Pot, Keijzer, \& De Bot, 2018). In light of the reported cognitive advantages of bilingualism (e.g. Bialystok \& Martin, 2004), it has been suggested that seniors could benefit from similar cognitive advantages by learning a new language (Antoniou, Gunasekera, \& Wong, 2013). This paper firstly outlines the relevant literature on foreign language learning and ageing. It then identifies methodological concerns and needs that are to be explored in experimental work related to third-age language learning if the line of research into cognitive benefits to ensue from this learning is to be fruitful.

\section{Life-long learning}

Lifelong bilingualism has been claimed to promote healthy ageing (Bialystok, 2016). The mental juggling of several languages is argued to transfer from the language control domain to the general cognitive control domain, provoking structural and functional brain changes (Luk, Bialystok, Craik, \& Grady, 2011). Moreover, multilingual speakers are assumed to build up cognitive reserve, delaying the onset of symptoms of degenerative diseases like Alzheimer's (Alladi et al., 2013). If these findings can be replicated on a large scale, bilingualism could be a powerful anti-ageing-disorder tool (Bak, Long, Vega-Mendoza, \& Sorace, 2016): Antoniou et al. (2013) suggested combining cognitive training programs and multilingualism, hypothesising that foreign language learning contributes significantly to cognitive reserve even in the absence of lifelong bilingualism. However, such studies predominantly target college-aged individuals. Extending this line of work to seniors is pertinent, as this is where cognitive flexibility is at its most vulnerable (Ramírez-Gómez, 2016).

Building on the now often debated studies examining the effects of lifelong bilingualism on seniors' cognitive functioning (Luk et al., 2011; Mukadam, Sommerlad, \& Livingston, 2017; Perani \& Abutalebi, 2015; Ramos, García, Antón, Casaponsa, \& Dunabeitia, 2017), a much smaller body of work explores whether foreign language learning in functionally monolingual seniors can have outcomes comparable to lifelong bilingualism. A handful of researchers have provided seniors with language training and measured the outcomes on cognition and the results are mixed: some studies found positive effects of language learning on cognition whereas others did not. Bak and colleagues (2016) offered a one-week Scottish Gaelic course to their 33 participants. Participants were not solely seniors but varied in age between 18 and 78. Additionally, an active and a passive control group were included ( $N=34$ together), where the active control group consisted of participants enrolled in courses such as art courses and documentary film 
courses. The results showed the language group to have significantly improved in attentional switching, measured through an Elevator Task. Pfenninger and Polz (2018) also found an effect of language learning, but in a different cognitive domain: they found the effect to mainly lie in enhanced inhibition skills. Their study included twelve German speakers and German-Slovenian bilinguals, all seniors (63-90 years old), who received a four-week intensive English course. During this period participants received three lessons of two hours a week. In addition to cognitive skills, the study also included measures of proficiency and socio-affective parameters to measure the linguistic and social outcomes of the course rather than solely focusing on cognitive ramifications. Pfenninger and Polz' results contrast starkly with those obtained by Ramos et al. (2017), who did not find any signs of improved cognitive functions in their study. Participants were 43 monolingual Spanish speakers who were either enrolled in an eightmonth Basque course or not taking any language course, and therefore served as a passive control group. No active control group other than language was included. The results showed that the groups did not differ in their switching abilities. Ware et al. (2017), finally, also did not find signs of improved cognitive functions due to late language learning. Their study comprised a four-month English course for French seniors (aged 63-90). A test of global cognitive functioning did not show any improvements between the pre-test and the post-test. Pot, Porkert and Keijzer (2019), in a meta-study on third-age language learning effect studies, ascribe the mixed findings to a number of inherent differences in the studies' design, pertaining to, among others, inclusion criteria for participants and intensity of the course.

\section{Problems in third-age language learning studies}

Specifically, the scantly available effect studies into third-age language learning differ in their (1) operationalisation of bilingualism, or in some cases a lack of operationalisation; (2) sample sizes, smaller samples (Pfenninger \& Polz, 2018; Ware et al., 2017) versus larger samples (Bak et al., 2016; Ramos et al., 2017); (3) inclusion of passive control groups (Ramos et al., 2017), passive and active control groups (Bak et al., 2016), or no control groups (Pfenninger \& Polz, 2018; Ware et al., 2017); (4) variation in duration of the training, ranging from one week (Bak et al., 2016) to eight months (Ramos et al., 2017); (5) variation in training intensity, from two hours a week (Ware et al., 2017) to fourteen (Bak et al., 2016); and (6) cognitive measures and cognitive tasks to measure cognitive outcomes. Regarding the latter, Ware and colleagues focussed on global cognitive functioning, whereas Ramos and colleagues focussed on switching abilities. Bak 
and colleagues as well as Pfenninger and Polz all investigated attention outcomes but measured attentional functions using different tasks: an Elevator Task and Alters-Konzentrations-Test, respectively. These six issues have been pointed out before in regards to lifelong bilingualism research, but suggestions to improve the research remain rather abstract (e.g. Antoniou, 2019).

In addition to different methods, all studies have one pitfall in common: seniors' language learning needs are not specifically addressed and incorporated into the research design (cf. Ramírez-Gómez, 2016), mostly because no unambiguous research results are available on this point. Ramírez-Gómez formulated the "critical foreign language gerontology" framework, an educational philosophy to empower and emancipate seniors regarding their language learning abilities. Unfortunately, the framework does not provide concrete guidelines for the senior foreign language learning classroom pedagogy, meaning that older learners' cognitive, psychological and social characteristics could not be taken into account in earlier work. And especially a combination of abovementioned characteristics needs to be taken into account as "aging is a complicated issue for learners, for it does not only deal with one issue, but a combination of issues, including both cognitive and social challenges" (Hsiao, 2018, p. 8). In most studies, however, the focus is either on the cognitive effects, the proficiency level, or well-being rather than the combination of the three, where a combination is more in line with ageing theories (Burke \& MacKay, 1997).

\section{Improving further research}

To develop tangible guidelines for teaching and learning foreign languages, more research is needed. Recent articles by Del Maschio, Fedeli and Abutalebi (2018), and Singleton and Pfenninger (2019) outline a number of proposals for continued and improved research targeting the effects of senior language learning. These proposals will be discussed before providing a research agenda.

Del Maschio and colleagues and Singleton and Pfenninger propose the following:

- Setting-up longitudinal studies consisting of dense data to predict short-term and long-term learner trajectories.

- Including and controlling for measures such as motivation, attitudes, wellbeing and leisure activities.

- Studying healthy seniors beginning to learn a new language or after a very long break of over 20 years.

- Including active as well as passive control groups. 
- Paying special attention to individual knowledge shown to drive neuroplasticity across age (e.g. music training) in abovementioned active control groups.

- Studying the effects of L2 learning on working memory capacity, where working memory is studied every six months for two years (or more).

- Combining behavioural and neuroimaging methods when studying cognitive outcomes of third-age language learning.

However relevant these guidelines are, many of the recommendations are generally true for second language acquisition (SLA) research and do not specifically relate to older language learners; opting for longitudinal designs, including and controlling for measures such as motivation, and combining behavioural and neuroimaging methods are not unique for third-age language learning. Fortunately, Del Maschio et al. (2018) and Singleton and Pfenninger (2019) also propose teaching guidelines specifically for seniors. These include a minimum instruction of four hours a week (although it is highly debatable that this is seniorspecific), and teaching materials that can be used in seniors' daily lives and extend the potential benefits of bilingualism "to the functional activities of daily living" (Del Maschio et al., 2018, p.12). One of the oldest papers focussing on senior language learning, although the age of seniors is not defined, is Schleppegrell's (1987) article which provides guidelines as to practices that should be avoided in the senior foreign language classroom. These practices include methods primarily relying on good auditory discrimination (since hearing declines with age), oral drills and memorisation (since such activities rely on short-term memory which declines with age), and timed activities (since processing speed declines with age). Conversely, the following three suggestions are put forward as encouraging the older adult learner: (1) eliminating affective barriers by reducing anxiety and building self-esteem; (2) making materials relevant and motivating by incorporating real life experiences that are life-stage appropriate and (3) encouraging the use of older adult learning strategies. These strategies refer to learning strategies that seniors have developed in life and that have served them well. However, most of the strategies Schleppegrell suggests are not specific to language teaching nor teaching seniors: every age group no matter what they learn should be motivated and needs relevant materials. And interestingly, Schleppegrell also suggests that language learning in seniors should focus on understanding rather than producing language although her reasons for suggesting this remain unclear. Yet what stands out most when we look at all three articles discussed above is that they only begin to scratch the surface of seniors' language learning needs. Specific teaching methods and their language learning outcomes for third-age learners, most importantly, are not discussed. 
There are a few studies looking into teaching strategies in the senior classroom. These studies mainly focus on implicit and explicit instruction. The difference between implicit and explicit language learning methods lies in the information concerning the metalinguistic input learners receive (Ellis, 1994; Norris \& Ortega, 2000). Explicit language learning is usually thought of as focus on forms (Long, 1991) which in practice translates to not only traditional grammar lessons but also explicit word translation lists. In implicit settings, students are expected to learn as a result of natural and abundant exposure. Most of the studies carried out in this domain focus on young adults. Implicit versus explicit instruction is complex and multidimensional, and no consensus has been reached as to which method works best (Andringa \& Rebuschat, 2015). A few studies regarding implicit vs. explicit teaching methods have been carried out with older adults. Midford and Kirsner (2005) compared younger (17-28) and older adults (58-74) on an artificial grammar learning task. Learning was operationalised as recognition accuracy of correct and incorrect grammar rules. Participants received implicit or explicit grammar instruction. In the implicit condition, without explanation of the rules, participants were shown the letter strings and were told that they had to learn and remember them. In the explicit condition, with explanation of the rules, participants were presented with a schematic diagram of the grammar, which was described and illustrated with examples. The results showed that the older group did relatively better in the implicit condition than the younger group. As an explanation the authors hypothesise that (1) implicit processes are relatively unimpaired in seniors and (2) complex knowledge domains, meaning without rules, encourage implicit processes, where seniors showed a relative advantage. The results of Midford and Kirsner's study are in line with Lenet, Sanz, Lado, Howard Jr. and Howard (2011), who looked at explicitness in feedback that learners received as part of Latin language training. Seniors (66-81) received vocabulary training followed by grammar training with feedback, including either explicit grammar explanations or simple good/wrong-only feedback. The second type of feedback was more effective for seniors: they performed better on the grammar tests. The authors do, however, mention that these results might be due to the fact that (1) the duration the feedback was presented in the explicit group was rather short and (2) that the explicit feedback might have distracted participants and encouraged them to try and memorise the rules. A common downside to both studies is that the training only consisted of a few sessions that corresponded to no more than a few hours in total and targeted only specific structures. Both have been pointed out as problematic in SLA research (respectively De Graaff, 1997; Rousse-Malpat \& Verspoor, 2012).

Since language learning needs of seniors thus remain a largely unexplored area, it becomes pertinent to temporarily abandon 'language' in 'language learn- 
ing needs' and explore the broader topic of learning needs in older adulthood. Whereas Del Maschio et al. (2018), Schleppegrell's (1987), and Singleton and Pfenninger (2019) mention alterations that need to be made for seniors, BoultonLewis \& Tam (2018) state that the teaching content or materials usually do not need to be changed for third-age learners. Teaching techniques, however, may need to be modified. These modifications mainly include allowing more time and practice (Charness, 1992), and taking possible sensory acuity problems into account, e.g. hearing loss (cf. Glass Jr, 1996). Seniors are furthermore claimed to prefer learning in groups where self-paced learning, hands-on activities, discussion, informality, and supportiveness are central (Boulton-Lewis \& Buys, 2015; Calhoun \& Gounard, 1979; Peterson \& Eden, 1981). Since the majority of seniors use technology, it is suggested to use technology in teaching to enrich the learning environment, even simply by using the internet (Boulton-Lewis \& Tam, 2018). More broadly speaking, learning needs also include social and well-being needs. The literature presents some of those social/affective needs although no consensus currently exists. According to Boulton-Lewis and Tam (2018), for example, seniors prefer informal learning whereas Delahaye and Ehrich (2008) mention they also prefer more formal learning. Hence, more data is needed as to how seniors want to learn (Boulton-Lewis, 2010).

\section{Future directions}

Third-age language learning is a relatively new and unexplored territory. In this paper we have outlined the research that has been conducted in the domain so far and we identified methodological concerns and knowledge gaps that need to be addressed when conducting experimental work related to third-age language learning. This can be translated to the following research agenda:

1. In third-age language learning studies, the suggestions put forward by Del Maschio et al. (2018) and Singleton and Pfenninger (2019), as described above, need to be incorporated to properly measure the potential cognitive benefits of language learning on cognition. More specifically, Del Maschio et al. and Singleton and Pfenninger mention studying the effects of language learning on working memory capacity only, whereas the studies discussed in Section 3 employ a variety of cognitive abilities. The field needs to decide which cognitive outcomes are studied in the light of delaying cognitive decline. And related to this is the need to define when these outcomes are big enough to actually count as an outcome. 
2. More important, however, is the need to study language learning needs in seniors as such an approach will help shape the way we teach seniors not only in research related to cognitive benefits but also in language teaching more generally. And seniors' needs should not only be studied in relation to language learning but also regarding seniors' social and well-being needs in a language course. One way to investigate this is by setting up a study asking seniors about their language learning and social/well-being needs and motivations. These considerations, however, cannot be generalised and have to be determined per culture and setting.

3. Regarding language learning needs, specific attention should be paid to teaching methods that work best for seniors. This extends from the realm of proficiency to cognition as well. As a starting point, we suggest that studies detail the specific outcome differences on cognition of implicit vs. explicit language teaching methods for seniors (see Howard Jr. \& Howard, 2013 for an overview on implicit/explicit learning). Additionally, differences in effects on cognition might be related to different types of knowledge. Investigating why one or the other works better, therefore, also deserves to be included in the research agenda.

4. There is little to no knowledge on proficiency gains from language learning in older adulthood. Most studies only focus on the cognitive gains and do not analyse what linguistics gains a language course provides seniors. For both practical and theoretical purposes, this should be incorporated in future studies. This can then be taken into account for future studies to define what will count as language outcomes.

5. Finally, we need to study abovementioned topics in unison. Studying cognition, proficiency, language learning needs and well-being as a whole will help paint a more complete picture of third-age language learning.

In addition to the scientific relevance that has been argued for in this paper, thirdage language learning studies have the possibility to make a societal contribution. This is two-fold; firstly, the need to communicate in unknown languages increases with mobility across the world (Gabryś-Barker, 2018) and secondly, there might be important clinical applications: language learning could enhance cognitive reserve and delay symptoms of age-related illnesses, but only when it is clearer what form such language learning should take.

\section{Funding}

Research funded by Gratama Stichting (2019-11) to Mara van der Ploeg. 


\section{References}

Alladi, S., Bak, T.H., Duggirala, V., Surampudi, B., Shailaja, M., Shukla, A. K., Chaudhuri, J. R., \& Kaul, S. (2013). Bilingualism delays age at onset of dementia, independent of education and immigration status. Neurology, 81(22), 1938-1944. https://doi.org/10.1212/01.wnl.0000436620.33155.a4

Andringa, S., \& Rebuschat, P. (2015). New directions in the study of implicit and explicit learning: An introduction. Studies in Second Language Acquisition, 37(2), 185-196. https://doi.org/10.1017/S027226311500008X

Antoniou, M. (2019). The advantages of bilingualism debate. Annual Review of Linguistics, 5, 395-415. https://doi.org/10.1146/annurev-linguistics-011718-011820

Antoniou, M., Gunasekera, G. M., \& Wong, P.C. (2013). Foreign language training as cognitive therapy for age-related cognitive decline: A hypothesis for future research. Neuroscience \& Biobehavioral Reviews, 37(10), 2689-2698. https://doi.org/10.1016/j.neubiorev.2013.09.004

Bak, T.H., Long, M.R., Vega-Mendoza, M., \& Sorace, A. (2016). Novelty, challenge, and practice: The impact of intensive language learning on attentional functions. PloS One, 11(4), e0153485. https://doi.org/10.1371/journal.pone.0153485

Bialystok, E. (2016). Aging and bilingualism. Linguistic Approaches to Bilingualism, 6(1), 1-8. https://doi.org/10.1075/lab.16004.bia

Bialystok, E., \& Martin, M.M. (2004). Attention and inhibition in bilingual children: Evidence from the dimensional change card sort task. Developmental Science, 7(3), 325-339. https://doi.org/10.1111/j.1467-7687.2004.00351.x

Boulton-Lewis, G. M. (2010). Education and learning for the elderly: Why, how, what. Educational gerontology, 36(3), 213-228. https://doi.org/10.1080/03601270903182877

Boulton-Lewis, G. M., \& Buys, L. (2015). Learning choices, older Australians and active ageing. Educational Gerontology, 41(11), 757-766. https://doi.org/10.1080/03601277.2015.1039455

Boulton-Lewis, G. M., \& Tam, M. (2018). Issues in teaching and learning for older adults in Hong Kong and Australia. Educational Gerontology, 44(10), 639-647. https://doi.org/10.1080/03601277.2018.1521902

Burke, D. M., \& MacKay, D.G. (1997). Memory, language, and ageing. Philosophical Transactions of the Royal Society of London. Series B: Biological Sciences, 352(1363), 1845-1856. https://doi.org/10.1098/rstb.1997.0170

Calhoun, R.O., \& Gounard, B. R. (1979). Meaningfulness, presentation rate, list length, and age in elderly adults' paired-associate learning. Educational Gerontology: An International Quarterly, 4(1), 49-56. https://doi.org/10.1080/0360127790040105

Charness, N. (1992). Age and expertise: Responding to Talland's challenge. In I.W. Poon, D. C. Rubin, \& B.A. Wilson (Eds.), Everyday cognition in adulthood and late life (pp. 437). Cambridge, UK: Cambridge University Press.

De Graaff, R. (1997). The eXperanto experiment. Studies in Second Language Acquisition, 19(02), 249-276. https://doi.org/10.1017/So272263197002064

Del Maschio, N., Fedeli, D., \& Abutalebi, J. (2018). Bilingualism and aging: Why research should continue. Linguistic Approaches to Bilingualism, 8, 2-19.

Delahaye, B.L., \& Ehrich, L.C. (2008). Complex learning preferences and strategies of older adults. Educational Gerontology, 34(8), 649-662. https://doi.org/10.1080/03601270801900875 
Ellis, N. (1994). Introduction: Implicit and explicit language learning - An overview. In N. Ellis (Ed.), Implicit and explicit learning of languages (pp. 79-114). London: Academic Press.

Gabryś-Barker, D. (2018). Introduction: The background. In D. Gabryś-Barker (Ed.), Third age learners of foreign languages (pp. xiii-xxvii). Bristol: Multilingual Matters.

Glass Jr, J.C. (1996). Factors affecting learning in older adults. Educational Gerontology: An International Quarterly, 22(4), 359-372. https://doi.org/10.1080/0360127960220405

He, W., Goodkind, D., \& Kowal, P. (2016). An aging world: 2015. Washington, D.C.: U.S. Government Publishing Office.

Hill, P.L., \& Turiano, N.A. (2014). Purpose in life as a predictor of mortality across adulthood. Psychological Science, 25(7), 1482-1486. https://doi.org/10.1177/0956797614531799

Howard Jr., J.H., \& Howard, D.V. (2013). Aging mind and brain: Is implicit learning spared in healthy aging? Frontiers in Psychology, 4, 817. https://doi.org/10.3389/fpsyg.2013.00817

Hsiao, S. (2018). Aging and ESL learning among older adult Chinese-speaking immigrants. Global Journal of Human-Social Science Research, 18(3), 1-10.

Lenet, A.E., Sanz, C., Lado, B., Howard Jr., J.H., \& Howard, D.V. (2011). Aging, pedagogical conditions, and differential success in SLA: An empirical study. In C. Sanz, \& R. P. Leow (Eds.), Implicit and explicit language learning: Conditions, processes, and knowledge in SLA and bilingualism (pp. 73-84). Georgetown: University Press.

Long, M.H. (1991). Focus on form: A design feature in language teaching methodology. In K. de Bot, R. Ginsberg, \& C. Kramsch (Eds.), Foreign language research in cross-cultural perspective (pp. 39-52). Amsterdam: John Benjamins. https://doi.org/10.1075/sibil.2.o7lon

Luk, G., Bialystok, E., Craik, F. I., \& Grady, C.L. (2011). Lifelong bilingualism maintains white matter integrity in older adults. Journal of Neuroscience, 31(46), 16808-16813. https://doi.org/10.1523/JNEUROSCl.4563-11.2011

Midford, R., \& Kirsner, K. (2005). Implicit and explicit learning in aged and young adults. Aging, Neuropsychology, and Cognition, 12(4), 359-387. https://doi.org/10.1080/13825580500246894

Mukadam, N., Sommerlad, A., \& Livingston, G. (2017). The relationship of bilingualism compared to monolingualism to the risk of cognitive decline or dementia: A systematic review and meta-analysis. Journal of Alzheimer's Disease, 58(1), 45-54. https://doi.org/10.3233/JAD-170131

Norris, J.M., \& Ortega, L. (2000). Effectiveness of L2 instruction: A research synthesis and quantitative meta-analysis. Language Learning, 50(3), 417-528. https://doi.org/10.1111/0023-8333.00136

Perani, D., \& Abutalebi, J. (2015). Bilingualism, dementia, cognitive and neural reserve. Current Opinion in Neurology, 28(6), 618-625. https://doi.org/10.1097/WCO.0000000000000267

Peterson, D.A., \& Eden, D.Z. (1981). Cognitive style and the older learner. Educational Gerontology: An International Quarterly, 7(1), 57-66. https://doi.org/10.1080/0360127810070107

Pfenninger, S.E., \& Polz, S. (2018). Foreign language learning in the third age: A pilot feasibility study on cognitive, socio-affective and linguistic drivers and benefits in relation to previous bilingualism of the learner. Journal of the European Second Language Association, 2(1), 1-13. https://doi.org/10.22599/jesla.36 
Pot, A., Keijzer, M., \& De Bot, K. (2018). Do low L2 abilities impede healthy aging for migrant older adults in the Netherlands? Dutch Journal of Applied Linguistics, 7(1), 109-120. https://doi.org/10.1075/dujal.17017.pot

Pot, A., Porkert, J., \& Keijzer, M. (2019). The bidirectional in bilingual: Cognitive, social and linguistic effects of and on third-age language learning. Behavioral Sciences, 9(9), 98. https://doi.org/10.3390/bs9090098

Ramírez-Gómez, D. (2016). Language teaching and the older adult: The significance of experience. Bristol; Buffalo: Multilingual Matters. https://doi.org/10.21832/9781783096305

Ramos, S., García, Y.F., Antón, E., Casaponsa, A., \& Dunabeitia, J.A. (2017). Does learning a language in the elderly enhance switching ability? Journal of Neurolinguistics, 43, 39-48. https://doi.org/10.1016/j.jneuroling.2016.09.001

Rousse-Malpat, A., \& Verspoor, M.H. (2012). Measuring effectiveness in focus on form versus focus on meaning. Dutch Journal of Applied Linguistics, 1(2), 263-276. https://doi.org/10.1075/dujal.1.2.07rou

Schleppegrell, M. (1987). The older language learner. Washington: ERIC Publications.

Singleton, D., \& Pfenninger, S.E. (2019). Exploring a poorly understood variable: An agenda for classroom research on the age factor. Language Teaching, 52(1), 111-127. https://doi.org/10.1017/So261444818000319

Ware, C., Damnee, S., Djabelkhir, L., Cristancho, V., Wu, Y., Benovici, J., Pino, M., \& Rigaud, A. (2017). Maintaining cognitive functioning in healthy seniors with a technology-based foreign language program: A pilot feasibility study. Frontiers in aging Neuroscience, 9, 42.

United Nations. (2017). World population prospects: The 2017 revision, key findings and advance tables. New York: Working Paper No. ESA/P/WP/248.

\section{Address for correspondence}

Mara van der Ploeg

University of Groningen

Oude Kijk in 't Jatstraat 26

9712 EK Groningen

The Netherlands

a.m.van.der.ploeg@rug.nl

https://orcid.org/oooo-0oo1-6303-3449

\section{Co-author information}

\author{
Merel Keijzer \\ University of Groningen \\ m.c.j.keijzer@rug.nl
}
Wander Lowie
University of Groningen
w.m.lowie@rug.nl 


\section{Publication history}

Date received: 16 July 2019

Date accepted: 7 August 2020

Published online: 16 October 2020 